\title{
Repúblicas del Nuevo Mundo
}

\section{(1) Daniel Gutiérrez Ardila}

Universidad Externado de Colombia, Colombia: daniel.gutierrez@uexternado.edu.co

Artículo recibido: 16 de junio de 2021 Aprobación final: 30 de septiembre de 2021

\section{Resumen}

Según muestra Hilda Sabato en su libro, el republicanismo en la Hispanoamérica decimonónica se caracterizó por su precocidad y por su consistencia política y social, mas también por su volatilidad. ¿Cómo explicar al mismo tiempo el arraigo histórico del sistema y su inestabilidad? Este ensayo retoma y discute las razones ideológicas e institucionales alegadas por la autora argentina y propone incluir otros factores en la ecuación.

Palabras clave: Republicanismo, Hispanoamérica, Modernidad, Inestabilidad, Revoluciones políticas.

\section{Republics of the New World}

\begin{abstract}
In Repúblicas del Nuevo Mundo..., Hilda Sabato claims that republicanism in nineteenth-century Spanish America was characterized by its precocity and its political and social consistency, but also by its volatility. How can we account for both the historical persistence of that system and its instability at the same time? This essay takes up and discusses the ideological and institutional reasons alleged by the Argentine author and proposes to include other factors in the equation.
\end{abstract}

Keywords: Republicanism, Spanish America, Modernity, Instability, Political Revolutions.

Vilipendiadas Repúblicas. Puede decirse que esta constatación es el punto de partida del libro de Hilda Sabato que, editado originalmente en inglés, se publica 
ahora por fortuna en español en una traducción al cuidado de la autora. Se trataba de una operación necesaria, inevitable, por cuanto los lugares comunes que la obra afronta y combate (en mi opinión con éxito) no son el resultado único de los apresurados juicios de especialistas extranjeros para quienes las Revoluciones atlánticas o el liberalismo se habrían manifestado aquí bajo el signo de la anomalía o la insignificancia. Dichos lugares comunes han prosperado, además, en algunos de los más publicitados esquemas explicativos de las ciencias sociales hechas a nuestra medida (por ejemplo, el de la "modernidad fallida") y constituyen, desgraciadamente, una parte esencial de las herramientas con que cuentan los ciudadanos de Latinoamérica para comprender y enfrentar la a menudo difícil realidad que los circunda. Así, las ideas simplificadoras y despreciativas sobre nuestra experiencia republicana suelen guiar la acción política, de manera tal que algo tiene que ver el tremendismo de los balances históricos y su eficaz vulgarización con las elecciones desesperadas o mesiánicas que muchas veces lamentamos.

Sabato cuestiona entonces estos modelos y propone en su lugar otro balance, más mesurado y sensato. Quiero insistir en estas dos virtudes del libro, pues la dificultad de la empresa consiste en forzar el contraste y en caer en una dinámica de oposición que termine erigiendo nuestras desapacibles Repúblicas en dechado de la democracia y el liberalismo. Sabato lo sabe y se cuida de ello: por eso su texto busca también proveer explicaciones acerca de la ostensible conflictividad de la vida política de la Hispanoamérica decimonónica.

El resultado de ambas exigencias (desafiar los esquematismos empobrecedores, señalando el valor de una experiencia histórica original, y comprender la volatilidad política de la región al mismo tiempo que la estabilidad de sus sistemas republicanos) es un sencillo (otra virtud del libro) sistema de generalizaciones cuidadosas, una búsqueda lograda de denominadores comunes o, en palabras de Sabato, de un "patrón compartido de los modos de funcionamiento" de "las relaciones entre pueblo y gobierno" en Hispanoamérica. Primer postulado: el principio de la soberanía popular, en su vertiente republicana, se impuso temprana y consistentemente. Segundo postulado: este principio abstracto y ordenador de lo político se manifestó sobre todo en "tres arenas de demarcación: las elecciones, la ciudadanía armada y la opinión pública”. El tercer postulado es cronológico y constituye una de las grandes contribuciones del libro: entre 1820 y 1870 la República en Hispanoamérica ("un tipo distintivo de orden republicano"), o mejor, las concepciones imperantes sobre la representación y las relaciones entre la sociedad y la política permitieron el cuestionamiento permanente de la autoridad y la impugnación de los gobernantes aun por la vía armada. Cuarto postulado: la participación política fue muy amplia y transversal en términos sociales, de modo que el chafarote, el dictador y el gamonal, que han terminado por convertirse en la quintaesencia de nuestra experiencia política vista desde adentro y desde afuera, son, en realidad, figuras marginales, caricaturas trágicas (por razones ya expresadas). Quinto postulado (íntimamente relacionado con los anteriores): el control de los gobernantes se expresó también a través de una idea plural de la soberanía, común a regímenes centralistas, federales y confederales, que concedió a la estructura miliciana un papel preponderante. 
Un siglo entonces, pero dos órdenes republicanos distintos, cuyo parteaguas es la década de 1870. De un lado, una idea unanimista de la política, revoluciones, preponderancia de las milicias y prensa militante. Del otro, partidos institucionalizados, búsqueda de la transparencia democrática, representación de minorías, caída en descrédito de las guerras civiles, triunfo del ejército y surgimiento del oficio periodístico.

Teniendo en mente el panorama general del libro, me propongo hacer a continuación algunos breves comentarios a propósito de los excesos y desbarros del republicanismo en el temprano siglo XIX hispanoamericano. En efecto, según nos recuerda Sabato, en la región "el conflicto dominó la vida política decimonónica”. Sé muy bien que toda una vertiente de la opinión pública elogió el arbitrio revolucionario como un remedio preciso contra el despotismo y como una herramienta necesaria para proseguir la tarea,iniciada durante la independencia, de demolición del orden colonial (visión liberal) o para salvaguardar el orden público y la paz social (visión conservadora). No es menos cierto, sin embargo, que la reiteración del recurso armado preocupó tempranamente a numerosos observadores de la vida política de cada país como una deriva indeseable y tormentosa. Repúblicas del Nuevo Mundo explica que la inestabilidad fue ocasionada por factores ideológicos (licitud de la lucha contra la tiranía, desconfianza a la concentración del poder...), así como por "formatos institucionales inadecuados para procesar el antagonismo". Siendo muy importantes, me parece que unos y otros no bastan para dar cuenta de la volatilidad política. En mi opinión hay que considerar al menos otros tres aspectos de la cuestión. El primero es la baja densidad demográfica y la extensión de estas Repúblicas, de todas, pues aun el territorio de las más pequeñas se acrecentaba considerablemente por la precariedad de las vías de comunicación. Sirva de ejemplo el caso neogranadino-colombiano: hasta mediados de siglo no existieron caminos carreteros en la sabana de Bogotá y la conexión expedita de la capital con el río Magdalena (por vía férrea) se hizo realidad únicamente a comienzos del siglo XX. El segundo es la morosidad económica, que impidió la pronta satisfacción de las exigencias igualitarias engendradas por la Independencia, la ejecución de planes ambiciosos y la financiación del más elemental gasto público (educación, obras públicas, justicia...). El tercero es la justificada paranoia que suscitaron las ambiciones monocráticas (José Antonio Páez en Venezuela, Juan Manuel de Rosas en el Río de la Plata, José Rafael Carrera en Guatemala...) y las agresiones externas (británicas, francesas, españolas, estadounidenses) contra el sistema de Repúblicas creadas tras el proceso independentista o contra su integridad territorial.

En suma, Estados muy extensos, poco poblados, pobres y constantemente amenazados en los que la autoridad se ejercía a caballo o a lomo de mula. En esas circunstancias la dispersión de la soberanía era una exigencia de gobierno y las revoluciones políticas, empresas sencillamente viables (ejemplar, en este sentido, el artículo de Malcolm Deas sobre Ricardo Gaitán Obeso y la guerra civil colombiana de 1885). Se dirá que son viejas explicaciones: ya Pierre Chaunu, en el manualito que consagró en 1949 a la historia de América Latina (en la colección Que sais-je), juzgaba evidentes los vínculos entre el desequilibrio político y el retraso 
económico y demográfico, de tal suerte que, para él, estos últimos explicaban el primero. Se trata, sin duda, de una ecuación incompleta, pero, ¿deben desaparecer por ello estos sumandos de la operación de interpretación histórica de la República hispanoamericana en el siglo XIX?

En cualquier caso, el parteaguas de la década de 1870 propuesto por Sabato se mantiene, porque fue entonces cuando inició el boom de la construcción de los ferrocarriles, que transformó la economía (posibilitando en muchas zonas la producción de excedentes agrícolas), la demografía (al menos en el Cono Sur, a través de la inmigración europea) y la política. Nada raro entonces que Rafael Núñez incluyera los trenes y los caminos en de su receta de la "paz científica", junto con las elecciones transparentes, la tolerancia política y religiosa, un ejército digno de ese nombre y el papel moneda (pensado como una forma de financiación ingeniosa para economías sedientas de capitales).

La justificada paranoia republicana es tan importante como los factores materiales (demografía, extensión, pobreza). Las ambiciones manifestadas por los altos oficiales de la independencia de perpetuarse en el poder o controlar la vida política, la diplomacia de los cañones ejercida por las grandes potencias ante el menor incidente consular, las expediciones promonárquicas patrocinadas por cortes europeas (en México, en Ecuador, en República Dominicana) o su apetito expansionista (en las costas del Perú, en el Istmo de Panamá, en Centroamérica) hicieron de la independencia y el republicanismo cuestiones candentes, de permanente actualidad. Aun en países como Nueva Granada-Colombia, descrito consistentemente por los escritores públicos locales como una tierra donde no prosperaba el caudillismo, el fantasma de Rosas, Páez o Carrera dio asidero a los temores engendrados por la figura de Tomás Cipriano de Mosquera y jugó un papel clave en el diseño constitucional de 1863: períodos presidenciales bianuales, prohibición de la reelección inmediata, prescindencia del gobierno general en las luchas armadas de los Estados, extrema dificultad de reforma de las instituciones fundamentales de la Unión...

No creo que se trate de un caso excepcional.

Me gustaría abordar también un factor psicológico que debió jugar un papel destacado en la volatilidad política de Hispanoamérica. Me refiero al crecimiento y desarrollo paroxístico de los Estados Unidos. En tiempos de la independencia se pensó que la forma republicana era la clave que permitiría replicar en el sur esa trayectoria virtuosa. Con el tiempo, sin embargo, el caso norteamericano dejó de ser un ejemplo para convertirse en un cuestionamiento angustiante: ¿por qué la independencia había generado allí orden y progreso, mientras que en Hispanoamérica era sinónimo de esperanzas defraudadas? La pregunta es qué tanto tuvo que ver esta constatación con la constante innovación institucional y con las álgidas polémicas (en ocasiones resueltas en el campo de batalla) que esta llevaba aparejadas. La cuestión federal con todos sus matices entra de lleno en esta materia. Me refiero a los debates sobre la conveniencia o inconveniencia de la implantación del modelo, sobre la capacidad o impreparación de los pueblos 
de origen hispano para regirse por él, sobre la necesidad de adaptarlo o sobre las críticas por su falseamiento, etc.

Pero hay más. Si había alguna diferencia capital entre la experiencia histórica de los Estados Unidos y la de las nuevas Repúblicas hispanoamericanas era el papel de la religión en la vida pública. Como señaló Rafael Núñez en sus Ensayos de crítica social (1874), en el primer caso la diversidad de comuniones era "infinita", a pesar de lo cual reinaba entre los diferentes sectarios la "más perfecta armonía”. ¿No era dicho rasgo una clave para entender la concordia reinante en la vida pública? Quizás hay algo de exageración en el balance de Núñez: lo importante es que aún para un hombre que conocía de primera mano la realidad norteamericana, existía un contraste preocupante entre ambas trayectorias republicanas. Se entiende entonces que para muchos resultara imprescindible combatir la primacía de la Iglesia, concebida como un obstáculo libre desarrollo de las instituciones democráticas. Estas sencillas constataciones estimularon, sin duda, el embate liberal contra las prerrogativas sociales y económicas de la Iglesia, cuestión esta que caldeó como ninguna otra los debates políticos (por lo menos en países como Nueva Granada-Colombia) y que está asombrosamente ausente del libro de Hilda Sabato (sin duda, tuvo razones para ello, por lo que me parecería muy interesante conocerlas). En cualquier caso, las frecuentes denuncias de los conservadores acerca de la imprudente importación de instituciones foráneas y, en especial, de la supuesta cruzada filo-protestante que habrían emprendido los liberales dan algún asidero a la hipótesis de que algún vínculo existió entre el anticlericalismo y el ejemplo lancinante de los Estados Unidos.

Quisiera concluir refiriéndome a un lugar común de las reflexiones políticas en la Hispanoamérica decimonónica: estas insistieron una y otra vez en la inexperiencia de los colonos de la región en lo relativo a las lides representativas y le otorgaron un valor explicativo, subrayando el lastre que ello significó para la vida independiente. A diferencia de los angloamericanos, que contaron con verdaderos órganos representativos, los cabildos habrían sido una escuela de vicios y malas prácticas. Quizás valga la pena retomar y desarrollar la idea y preguntarse si, efectivamente, la separación de España generó cambios políticos y sociales más rupturistas y por ello mismo más difíciles de asimilar (no está de más recordar que los norteamericanos hicieron su revolución en nombre de una tradición de gobierno falseada por la metrópoli). Hispanoamérica se distinguía por la complejidad de sus jerarquías raciales (en lugar del sistema bipolar, blanco y negro, de las colonias inglesas, para retomar los términos empleados por Robin Blackburn). Además, la larga guerra contra la metrópoli, el carácter intempestivo del republicanismo resultante (en el contexto de las Restauraciones) y las amenazas que debió enfrentar a lo largo del siglo, así como el arduo despegue económico compusieron un escenario tormentoso: exigencias crecientes, recursos escasos, prerrogativas asediadas e incremento de la competencia política.

Repúblicas del Nuevo Mundo es una obra sosegada, clara y corta, virtudes todas que lo hacen recomendable para un público amplio y especialmente para los historiadores, abstraídos por lo general en la confección de artículos para revistas 
especializadas o de libros de escaso tiraje y circulación. Es también una obra general, y por ello muy ambiciosa, pues abarca un área gigantesca (en términos geográficos e históricos), lo que de nuevo ofrece un contraste saludable con la tendencia del gremio a privilegiar el estudio de períodos limitados y de cuestiones muy acotadas. Los comentarios precedentes son una manera de saludar la apuesta y sus resultados y una invitación para que Hilda Sabato comparta con nosotros las razones de ciertas decisiones que presidieron la redacción del libro. 